\title{
DETETIVE BRISCO: SÉRIE EDUCATIVA DE INVESTIGAÇÃO PROFISSIONAL
}

CURITIBA/PR MAIO/2018

\author{
Antoine Youssef Kamel - UNINTER - antoine12@gmail.com \\ Débora Cristina Veneral - UNINTER - DEBORA.V@UNINTER.com \\ Daniele Assad Gonçalves - UNINTER - DANIELE.Go@uninter.com \\ Alvaro Martins Fernandes Júnior - UNINTER - ALVARO.FE@uninter.com \\ Talita Juliana Sabião - UNINTER - TALITA.S@uninter.com \\ Lucas Massimo Tonial Antunes de Souza - UNINTER - LUCAS.SO@uninter.com
}

Tipo: Relato de Experiência Inovadora (EI)

Categoria: Métodos e Tecnologias

Setor Educacional: EDUCAÇÃO SUPERIOR

\begin{abstract}
RESUMO
O presente artigo apresenta a concepção, criação e desenvolvimento de um pequeno projeto narrativo denominado Detetive Brisco. Trata-se de uma série inicialmente em áudio, e posteriormente animação, relatando o trabalho do detetive particular Franke Brisco. A ideia da série fictícia é ensinar técnicas da investigação de maneira descontraída e, principalmente, instigar a curiosidade de atuais $e$ futuros detetives. Desta maneira, procura-se diversificar os recursos empregados na educação a distância, mesclando educação e entretenimento, com o fito de melhorar a educação e, prendendo a atenção e o interesse dos alunos, retê-los, evitando a evasão.
\end{abstract}

Palavras-chave: Tecnologia aplicada à educação a distância; Programa de rádio educativo; Audionovela de detetive particular; Graduação em Investigação Profissional; Desenvolvimento de recursos educacionais digitais.

\section{AGRADECIMENTOS}

MUITO OBRIGADO A CADA COLEGA DE TRABALHO DA UNINTER, QUE INSPIRA E DÁ FORÇA AOS PROJETOS DE CADA UM E OS INSPIRA A BUSCAR TRANSFORMAR A EDUCAÇÃO POR GRANDES GESTOS E PEQUENOS PASSOS. 


\section{Introdução}

Apresenta-se aqui a experiência de concepção e desenvolvimento de Detetive Brisco, uma série investigativa em formato de áudio e animação.

Há muitos filmes e séries que relatam experiências de investigação policial, tão conhecidos que sequer é necessário aqui mencionar seus nomes. Esses programas trazem histórias cujo ponto de partida é a área pública, visto que se exige, para os procedimentos adotados, prerrogativas e responsabilidades cabíveis com exclusividade aos agentes que atuam diretamente na segurança pública ou em estrita cooperação com órgãos públicos.

Além de não terem cunho educacional, as séries e filmes que eventualmente busquem traduzir apenas a realidade em suas temáticas de investigação não refletem a atuação de investigadores privados, mais conhecidos como detetives particulares. Estes contam com severas limitações à atuação, não tendo possibilidade legal, por exemplo, de exigir o interrogatório de pessoas ou de requerer judicialmente o acesso de dados de particulares protegidos constitucionalmente, além de somente poderem colaborar em investigações policiais com autorização da pessoa que o contratou e aceitação do delegado de polícia, nos termos da lei regulamentadora recentemente promulgada (Lei n. 13.432, de 11 de abril de 2017).

Por isso, Detetive Brisco é um projeto inovador, sendo - até onde se sabe - o único projeto que aplica a narrativa ficcional (em áudio e animação) para a educação de detetives, isto é, investigadores privados.

Cabe ainda mencionar que o primeiro curso superior na área, o curso superior de Investigação Profissional da UNINTER, iniciou sua primeira turma em fevereiro de 2018, e é precisamente no âmbito do curso que é criado este primeiro projeto narrativo educacional.

\section{Objetivos}

O objetivo deste trabalho é demonstrar a aplicação da teoria - no campo de comunicação, tecnologias e construção de recursos educacionais - à prática do desenvolvimento de uma série investigativa nos formatos audiodrama e animação. 
A série é pensada sob o duplo caráter de um programa educativo: servir de entretenimento ao mesmo tempo em que é empregada na educação.

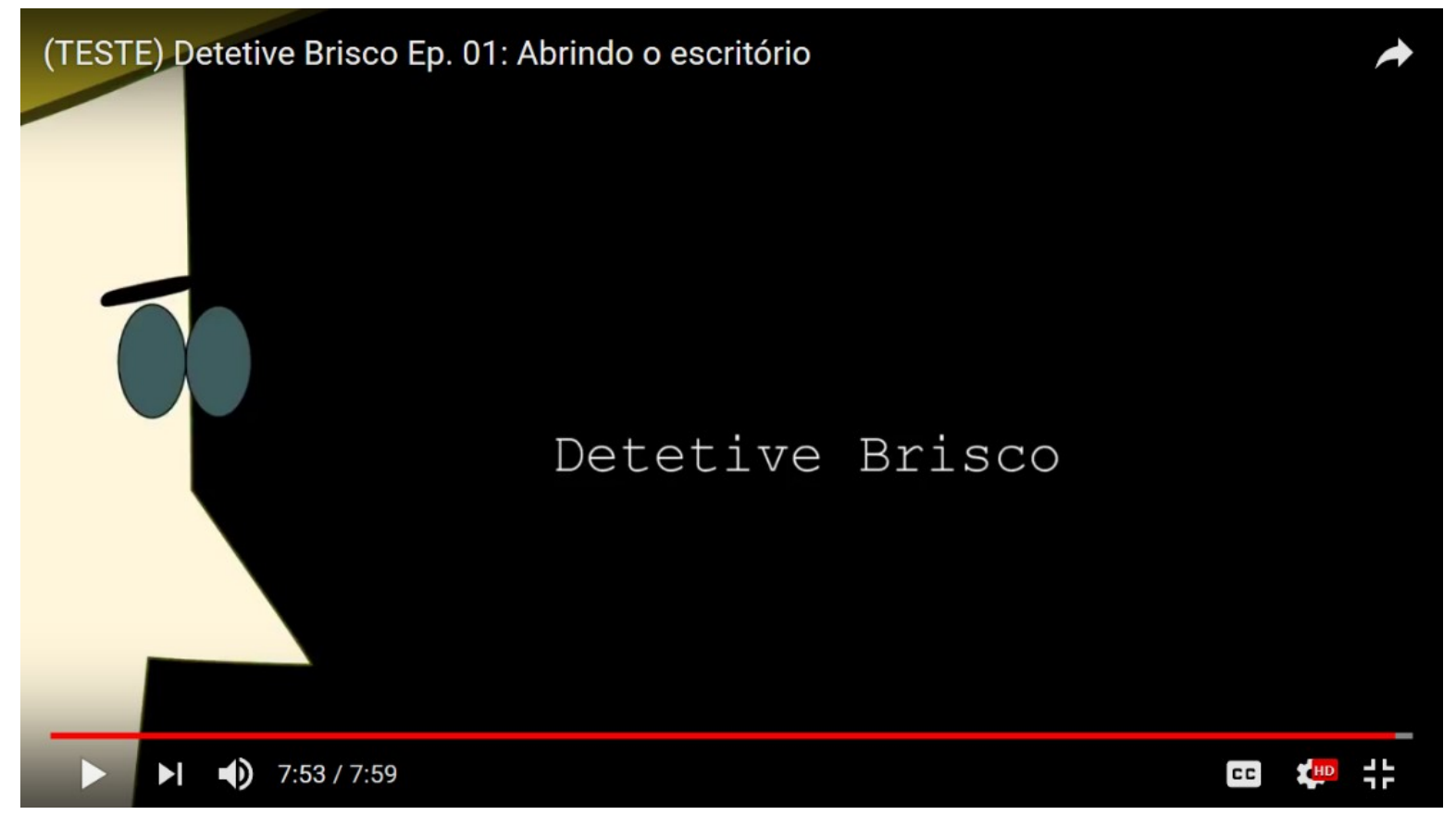

Figura 1: Projeto gráfico estático, elaborado como teste para submissão do áudio do primeiro episódio no YouTube.

Com este relato, busca-se também inspirar educadores e pensadores a exercitar a criatividade na criação de conteúdo semelhante com eficácia, que mesclem entretenimento e educação em doses sábias; pois, se não houver educação, não serve ao propósito, e se não houver uma narrativa interessante, não evoca o lado do entretenimento e pode prejudicar o interesse de alunos pelo projeto.

\section{Referencial teórico}

Robin (2018), com base nos estudos do Center For Digital Storytelling (CDS, "Centro para a Contação Digital de Histórias"), sediado em Berkeley, Califórnia, declara o que considera ser os sete elementos da contação digital de histórias:

1. Ponto de vista: qual o mote da história e a perspectiva do autor?

2. Uma questão dramática: uma questão-chave que mantém a atenção do espectador e será respondida ao final da história. 
3. Conteúdo emocional: assuntos sérios que vêm à tona conectam a audiência à história.

4. O dom da voz: a voz (timbre, volume, entonação) personaliza a história e ajuda o espectador a compreender o contexto.

5. O poder da trilha sonora: música e outros sons que amparam e embelezam a história.

6. Economia: utilizar somente o conteúdo necessário para contar a história e não sobrecarregar a audiência.

7. Ritmo: o quão devagar ou velozmente a história progride.

O autor acrescenta que os requisitos específicos da contação de uma história digital, acima delineados, são um pouco diferentes desses sete elementos se for uma história para a educação. Os elementos propostos pelo autor, baseando-se naqueles do CDS, são dez:

1. O propósito geral da história.

2. O ponto de vista do narrador.

3. A questão ou as questões dramáticas.

4. A escolha do conteúdo.

5. Clareza da voz.

6. Ritmo da narrativa.

7. Uso de uma trilha sonora significativa ("meaningful áudio soundtrack").

8. Qualidade das imagens, do vídeo e outros elementos multimídia.

9. Economia dos detalhes da história

10. Boa gramática e uso da linguagem (Robin, 2018, tradução livre).

A educação multimídia - que se vale de diferentes canais sensoriais ao mesmo tempo —, se bem utilizada, se traduz em maior aprendizado para o destinatário. Para Mayer (2005), utilizar bem os recursos tem, como um dos pontos necessários, a estrutura coerente: excluir o que é inócuo, sons, imagens e tarefas sem relevância para o aprendizado. 


\section{Procedimentos metodológicos}

Este trabalho é, assim, um relato de experiência, especificamente sobre o desenvolvimento da série com finalidade educativa, descrevendo-se as tarefas realizadas para o projeto e algumas teorias da educação associadas a ele.

\section{O processo de desenvolvimento da série}

Para o desenvolvimento da série, especificamente de seu primeiro episódio, foi pensado o seu objetivo, então elaborado o roteiro e, então, contatados colegas da academia para que o roteiro saísse do papel, especialmente a voz dos personagens e a edição do áudio.

A série acompanha o detetive Frank Brisco em seu trabalho, instigando a imaginação criativa - virtude essencial de um detetive - e a reflexão sobre as atividades de um investigador particular.

São basicamente dois os objetivos principais da série, a partir dos quais foi pensado o projeto: instigar (reflexão) e capacitar (no uso de técnicas e ferramentas). Com esta produção sobre um detetive particular, procurou-se despertar, em atuais e futuros detetives, o interesse e a curiosidade, requisitos fundamentais de um investigador. A partir da série fictícia, ao mesmo tempo em que se contribui para a formação de profissionais, inspira-se nos estudantes e profissionais de investigação a reflexão sobre o cotidiano e os desafios de um investigador profissional.

O projeto foi inicialmente pensado como puro áudio, com possibilidade de veiculação via internet e, eventualmente, ofertado a emissoras de rádio para transmissão gratuitamente - algo não descartado. 


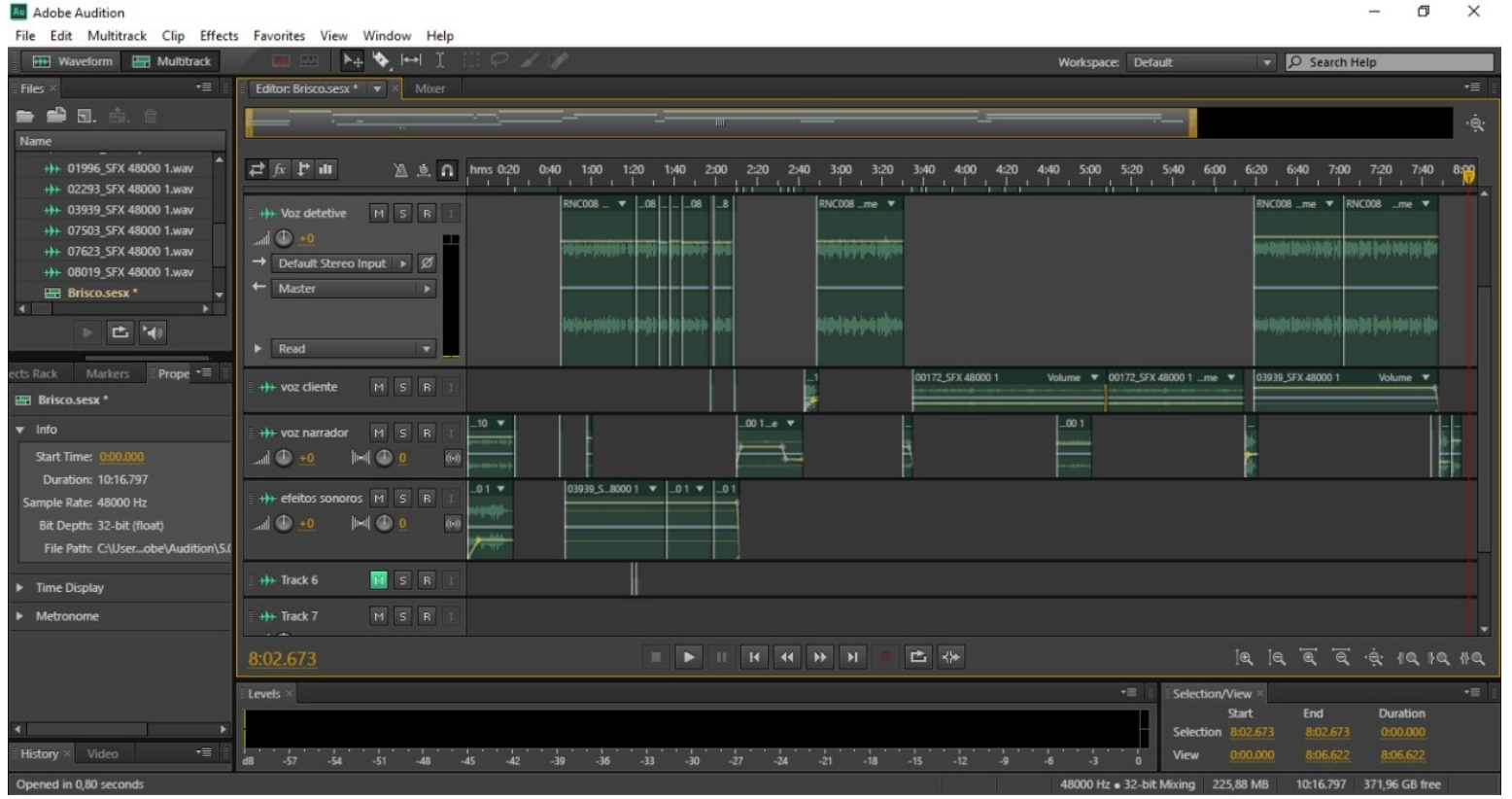

Figura 2: Concepção inicial de Detetive Brisco: somente em áudio, no formato audionovela ou audiodrama.

Todavia, os meios de divulgação eram pensados enquanto se produziam os demais episódios: canal de vídeo online (YouTube), página do Facebook e outras formas de divulgação.

Assim, posteriormente, mas ainda antes da divulgação oficial do primeiro episódio, surgiu a ideia de se criar um material visual mais elaborado, sendo viável - em termos de recursos e expertise - a criação de uma animação, como se vê na figura abaixo.

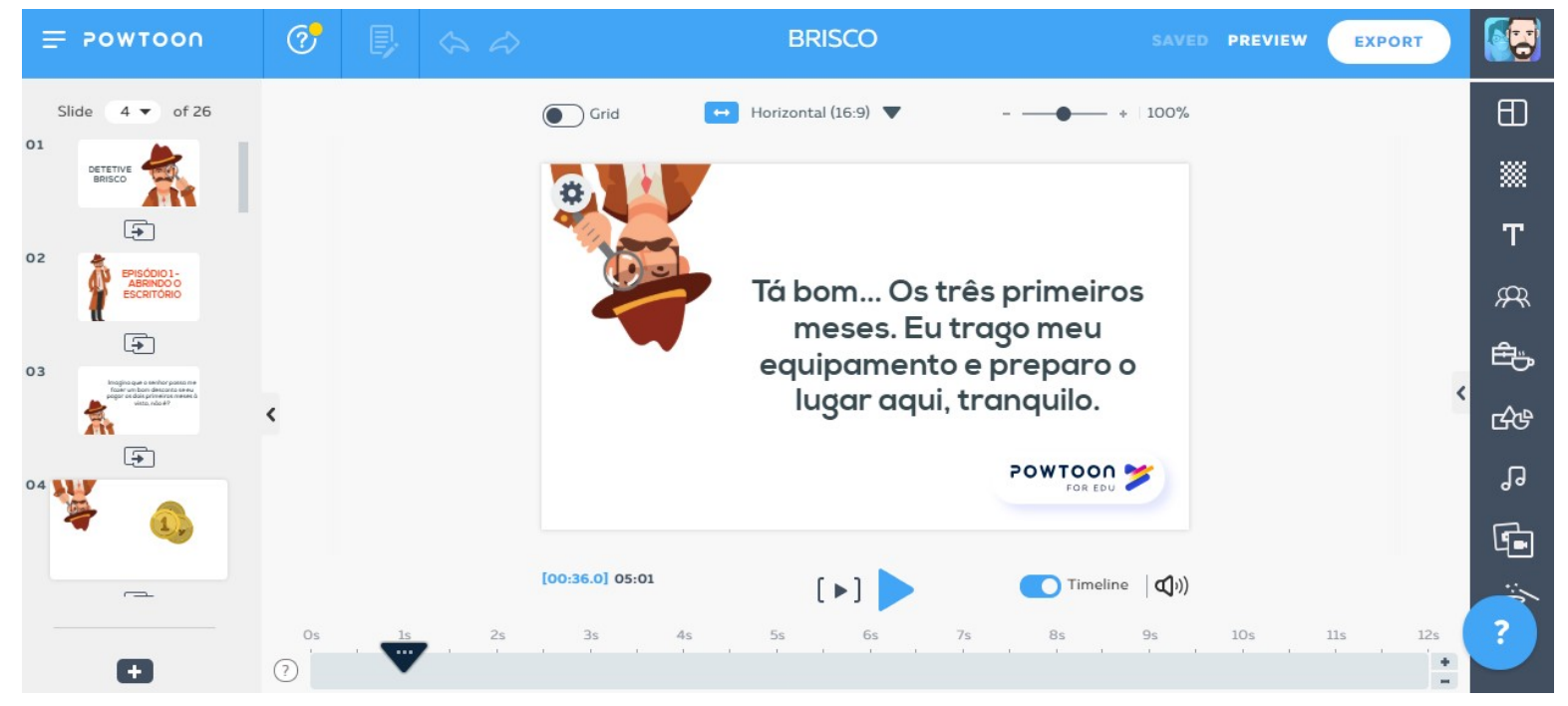

Figura 3: Tela da animação criada para o episódio 01 de Detetive Brisco, mostrando 
todo o ambiente da ferramenta utilizada (Powtoon).

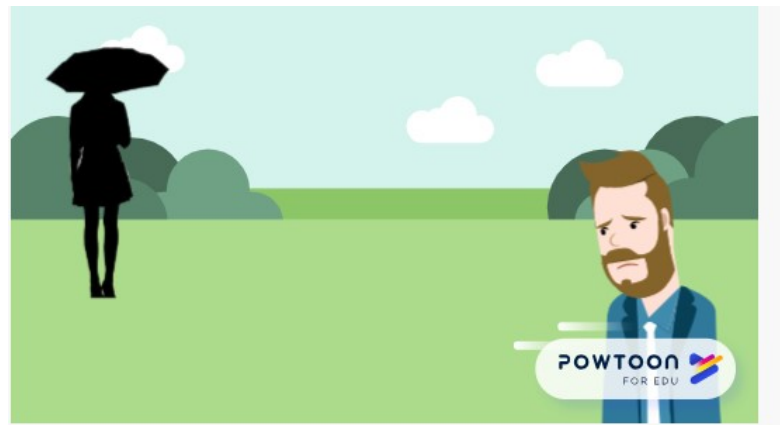

[04:43.0] 05:01 $[\bullet]$

(OTimeline (ه))

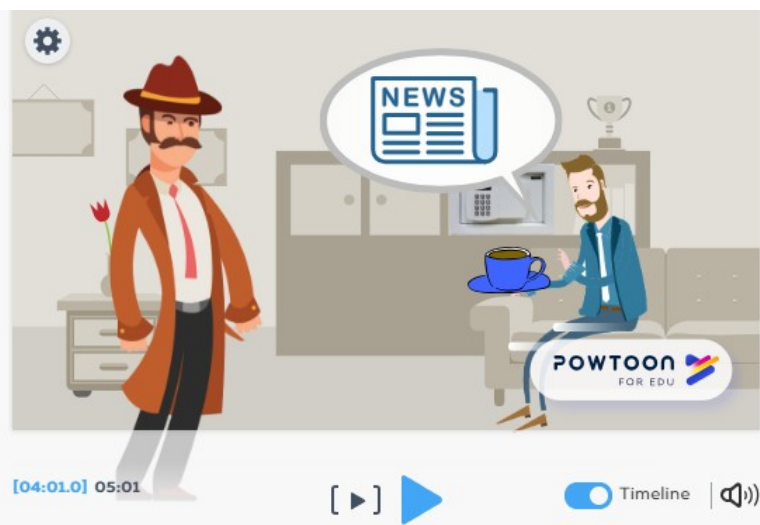

Figura 4: Telas da animação criada para o episódio 01 de Detetive Brisco.
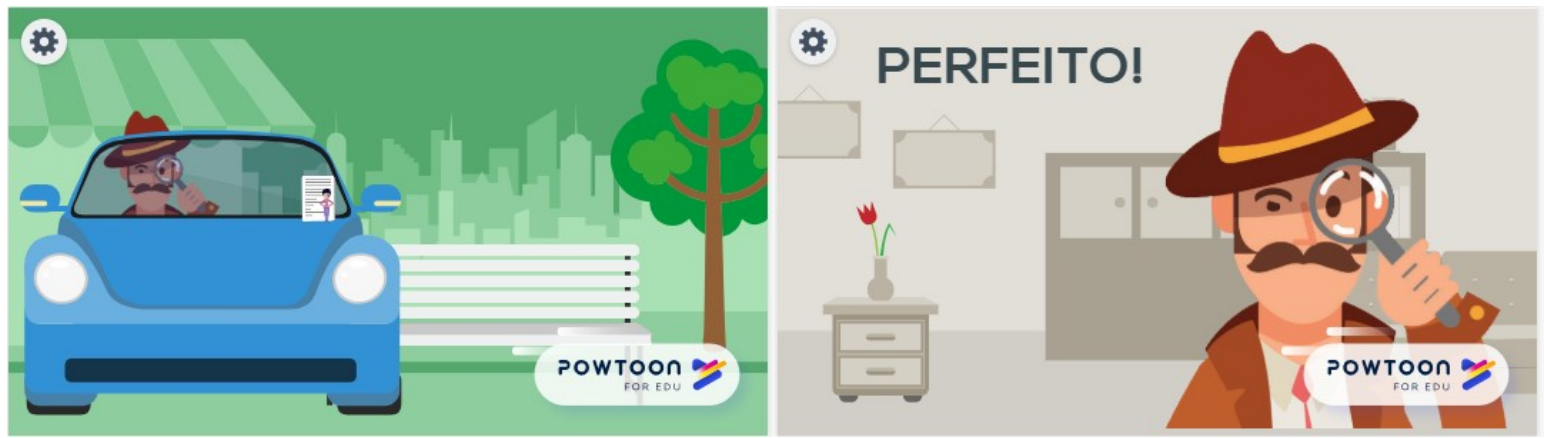

Figura 5: Outras telas da animação criada para o episódio 01 de Detetive Brisco.

A elaboração de uma história varia em maior ou menor escala a depender da forma pensada para sua produção (se áudio, vídeo gravado, animação etc.) e divulgação 
(internet, televisão rádio) (MCLUHAN, 2005). Desta maneira, ao ser elaborado e gravado o áudio do primeiro episódio, pensando-se na veiculação por meio apenas auditivo, a narração de ações é bastante presente; se fosse pensada a animação desde o início, possivelmente haveria menor participação da narradora. Esse fato, se por um lado pode ser negativo por significar conteúdo que poderia ser cortado sem maior prejuízo (economia, nos termos do CDS), possivelmente não é notado pelo espectador e é bastante positivo por possibilitar o usufruto do conteúdo apenas em áudio, se desejado.

\section{Resultados}

Não se espera que a série narrativa venha a substituir os recursos utilizados como pilares no curso, ofertado na modalidade a distância: videoaulas, resolução de dúvidas com tutores presenciais (nos polos de apoio presencial) e a distância (na sede da IES, por meio do ambiente virtual de aprendizagem), textos e interação com os colegas por meio de fóruns, incluindo o relato de casos reais enfrentados por detetives particulares como forma de aprendizagem.

Porém, a série é um recurso educacional adicional com o qual espera-se agregar valor à formação dos alunos da graduação em Investigação Profissional, na modalidade EAD. Tratando-se, ainda, de um recurso de aprendizagem livremente disponível na internet, trará frutos à vida dos presentes e futuros profissionais de investigação.

Por claro que, pela qualidade educacional, o projeto há de servir, ainda, como forma de divulgação da profissão de investigador profissional e do curso superior recém-criado, fazendo com que estudantes de todo o Brasil conheçam mais uma oportunidade dentro do ensino superior que poderá condizer à vocação de cada um.

\section{Considerações finais}

Foi visto que uma série ou outro projeto narrativo deve mesclar entretenimento e educação pois, sem objetivo educacional, não serve, e se não houver prazer entretenimento - , o propósito de educar por meio de uma narrativa não evoca toda a sua eficácia. Procura-se, com projetos como este, diversificar os recursos empregados na educação a distância, mesclando educação e entretenimento, com o fito de melhorar a 
educação e, prendendo a atenção e o interesse dos alunos, retê-los, evitando a evasão.

O processo de elaboração de um conteúdo de qualidade, qualquer espécie de conteúdo, é trabalhoso e envolve o trabalho de outras pessoas de diversas áreas. Para uma narrativa com finalidade educacional, os desafios também existem. As ideias, o roteiro e a implementação (em especial gravação e edição do áudio ou da animação) exigem criatividade e tempo, com o resultado glorioso de que, ao final, se tenha o melhor produto possível para o fim esperado de aperfeiçoamento dos estudantes.

Assim, procurou-se aqui mostrar de forma breve e singela a criação de uma narrativa com foco na Educação a Distância e, consequentemente, reforçar a possibilidade de criação e utilização da narrativa criativa e ficcional no ensino superior.

\section{Referências}

Bloom, Benjamin S. Taxonomy of Educational Objectives, v. 1: Cognitive Domain. New York: McKay, 1956.

CORTELAZZO, Iolanda Bueno de Camargo. Prática pedagógica, Aprendizagem e Avaliação em Educação a Distância. Curitiba: Intersaberes, 2013.

FARIA, Adriano Antônio; LOPES, Luís Fernando. Práticas Pedagógicas em EAD. Curitiba: InterSaberes, 2014.

FERNANDES JÚNIOR, Alvaro Martins. Gestão do Conhecimento na Educação Básica Brasileira: Conexão 3.0, a Hipermídia das Crianças. 2015. 163 f. Dissertação (Mestrado em Gestão do Conhecimento nas Organizações) - Centro Universitário Cesumar (Unicesumar), Maringá, 2015. Disponível em: . Acesso em: 16 maio 2018.

GONZALEZ, Mathias. Fundamentos da Tutoria em Educação a Distância. São Paulo: Avercamp, 2005.

MATTAR, João. Design Educacional: Educação a Distância na Prática. São Paulo: Artesanato, 2014.

MAYER, Richard E. Cognitive theory of multimedia learning. In: The Cambridge Handbook of Multimedia Learning. New York: Cambridge University Press, 2005. 
MCLUHAN, Marshall. Os Meios de comunicação como extensões do homem. Tradução de Décio Pignatari. 14. ed. São Paulo: Cultrix, 2005.

ROBIN, Bernard. Educational Uses of Digital Storytelling. University of Houston College of Education. Disponível em: . Acesso em: 16 maio 2018. 